\title{
Role of risk of malignancy index 4 in evaluation of adnexal masses
}

\author{
Amarjeet Kaur ${ }^{1 *}$, Sujata Sharma1, Sohan Singh²
}

${ }^{1}$ Department of Obstetrics and Gynecology, Govt. Medical College, Amritsar, Punjab, India
${ }^{2}$ Department of Radiodiagnosis and Imaging, Govt. Medical College, Amritsar, Punjab, India

Received: 15 July 2020

Accepted: 07 August 2020

*Correspondence:

Dr. Amarjeet Kaur,

E-mail: amarjeet11145@gmail.com

Copyright: (c) the author(s), publisher and licensee Medip Academy. This is an open-access article distributed under the terms of the Creative Commons Attribution Non-Commercial License, which permits unrestricted non-commercial use, distribution, and reproduction in any medium, provided the original work is properly cited.

\begin{abstract}
Background: The discrimination between benign and malignant adnexal masses is important for clinical management and surgical planning in such patients. Various combined methods of evaluation adnexal mass have also been proposed. Risk of malignancy index (RMI) is a combined parameter which is simple, preclinical and highly sensitive, and more specific. Risk of malignancy index 4 (RMI 4) is calculated as a product of ultrasound score (U) $\times$ menopausal score $(\mathrm{M}) \times \mathrm{CA} 125 \times$ tumor size. Objective of this study was to determine if the RMI (RMI 4) can distinguish between benign and malignant adnexal masses.

Methods: A prospective study was conducted on 30 women with an adnexal mass presenting in the OPD and emergency and RMI-4 calculated. Cut off level of 450 was set to differentiate between benign and malignant mass.

Results: In this study, the value of RMI-4 is less than 450 in 17 patients with benign disease and 3 patients with malignant disease. The value is more than 450 in 2 patients with benign disease and 8 patients with malignant disease. RMI-4 $>450$ had a sensitivity of $72.73 \%$ and specificity is $89.47 \%$. The positive predictive value is $80 \%$ and negative predictive value is $85 \%$. The p-value for RMI-4 in this study is 0.001 which is highly significant.

Conclusions: RMI is a reliable, simple, easy to use and cost-effective method in differentiating benign from malignant adnexal masses.
\end{abstract}

Keywords: Adnexal mass, CA 125, Risk of malignancy index-4, Ultrasound score

\section{INTRODUCTION}

Pelvic mass is one of the most common clinical presentation, representing a number of benign and malignant conditions. Presence of an adnexal mass presents a diagnostic dilemma. ${ }^{1}$ However, it is essential to differentiate between benign and malignant masses for the accurate management of the patients. Sometimes non gynaecologic conditions may simulate adnexal masses and may be considered in their differential diagnosis. Adnexal masses may be of ovarian, uterine, gastrointestinal, tubal or genitourinary origin. Common adnexal masses and their differential diagnosis are ovarian (ovarian neoplasm, ovarian cyst, endometriosis, tubo-ovarian mass), uterine (myomas), gastrointestinal (diverticulitis, appendicular mass), tubal pathology (ectopic pregnancy, hydrosalpinx/pyosalpinx, tubal neoplasms) and genitourinary (pelvic kidney)., ${ }^{2,3}$

\section{Evaluation of adnexal masses}

Adnexal masses are evaluated by clinical examination, imaging (ultrasonography, Doppler scan, abdominal radiography, CT/MRI/PET scan), tumor markers (CA 125), combined methods (RMI, ADNEX method, IOTA simple rules, LR2 method) and histopathology. ${ }^{4}$

In most cases, however, the history and physical examination alone are insufficient to make a diagnosis, and ultrasound imaging, with or without laboratory studies, is necessary. The ultimate diagnostic tool is histological examination. ${ }^{4}$ 
CA 125, one of the biochemical markers, is often used for distinguishing malignant tumors. ${ }^{5-7}$ However, CA 125 has limited value. Ultrasound examination, more specifically subjective assessment by an expert examiner, is considered the best way to differentiate malignant from benign adnexal masses prior to surgery. ${ }^{8-10}$

Risk of malignancy index (RMI) is a combined parameter which is simple, preclinical and highly sensitive, and more specific. The main advantage of RMI is that it is a simple scoring system that can be applied directly into clinical practice without the introduction of expensive or complicated methods (such as computed tomography scan, magnetic resonance imaging and whole-body emission tomography). Four versions of RMI have been proposed i.e., RMI 1, RMI 2, RMI 3 and RMI 4. The sensitivity and specificity of each version of RMI have been studied in various studies. RMI 4 is the recent version that also includes tumor size and is considered to be more reliable as compared to previous versions. ${ }^{11}$

RMI 4 is calculated as $\mathrm{U}$ (ultrasound score) $\times \mathrm{M}$ (menopausal score) $\times \mathrm{S}$ (size in centimetres) $\times \mathrm{CA} 125$. A score is assigned for the following ultrasound features, which are suggestive of malignancy: presence of a multilocular cystic lesion, solid areas, bilateral lesions, ascites, and intra-abdominal metastases, which each receives a score of one point. A total ultrasound score of 0 or 1 is $U=1$, and a score of $>2$ is $U=4$. Premenopausal status is $M=1$ and postmenopausal status is $M=4$. A tumor size (single greatest diameter) of $<7 \mathrm{~cm}$ is $\mathrm{S}=1$, and $>7 \mathrm{~cm}$ is $\mathrm{S}=2$. The serum level of CA125 is applied directly to the calculation. ${ }^{11}$

\section{Aims and objectives}

Aims and objectives of the study were to find the risk of malignancy index 4 among women with adnexal masses and to evaluate its ability to discriminate benign mass from a malignant pelvic mass.

\section{METHODS}

This was a prospective study including 30 random women with adnexal masses attending OPD and emergency of department of obstetrics and gynecology, Govt. Medical College, Amritsar. This study was conducted after taking permission from thesis and ethical committee of our institution. After obtaining informed consent from all patients, a full history was obtained and a general and gynecological examination was performed. Subjects then underwent a transvaginal or transabdominal ultrasound in the department of radiodiagnosis, Govt. Medical College, Amritsar.

Patient's preoperative ultrasound findings, serum CA125 levels, and menopausal status were noted. A total ultrasound score (U) was calculated for each patient after assessing all the five parameters. Ultrasound was performed for measurement of tumor size $(S)$ for each patient. Ultrasound score was assigned $U=1$ if 0 or 1 criteria fulfilled and ultrasound score $U=4$ if 2 or more criteria was fulfilled. Menopausal status was noted. Menopause was defined as one or more year of amenorrhea or women who had undergone hysterectomy. Menopausal score was assigned $\mathrm{M}=1$ if premenopausal and $\mathrm{M}=4$ if postmenopausal.

\section{Inclusion criteria}

Women with adnexal masses attending OPD or emergency, and willing for FNAC/histopathological examination/surgical procedure were included in this study.

\section{Exclusion criteria}

Women with functional cyst $<5 \mathrm{~cm}$, subject with evidence of hepatic, peritoneal metastasis or lung metastasis were excluded from this study.

Based on data obtained RMI 4 was calculated. The serum level of CA 125 was applied directly to the calculation.

Subjects were then posted for surgical exploration/FNAC. Specimen of adnexal mass were sent for histopathological examination in the department of pathology, Govt. Medical College, Amritsar. Histopathological results were analyzed for correlation with RMI 4.

\section{Statistical analysis}

The ' $t$ '-test for the means and the Chi-square test was used to compare the demographic, biochemical and ultrasonographic data of subjects with benign and malignant adnexal masses. The SPSS software was used in performance of statistical analysis. In this study the variable was RMI 4 and outcome was malignant nature of adnexal mass.

\section{RESULTS}

The above table showed the age distribution of the study population. The p-value was $0.311 \quad(>0.05)$ which indicated that there was no significant correlation between occurrence of benign and malignant disease and age in the present study. This could be explained by the relatively younger age of subjects with malignant disease in the present study.

There was no statistically significant correlation between menopausal status and occurrence of benign and malignant disease in the present study (p-0.563). This showed that menopausal status was not a predictor of ovarian malignancy.

The sensitivity of menopausal score in diagnosing malignancy was $36.36 \%$ and specificity was $73.68 \%$. The positive predictive value was $44.44 \%$ and negative predictive value was $66.67 \%$ in the study. 
Table 1: Distribution of subjects by age $(n=30)$.

\begin{tabular}{|c|c|c|c|c|}
\hline Age group (in years) & Benign $(n=19)$ & Malignant (n=11) & Total $(n=30)$ & P-value \\
\hline$<30$ & $5(50)$ & $5(50)$ & $10(100)$ & \multirow{5}{*}{0.311} \\
\hline $30-44$ & $9(81.8)$ & $2(18.18)$ & $11(100)$ & \\
\hline $45-54$ & $4(66.66)$ & $2(33.33)$ & $6(100)$ & \\
\hline$>55$ & $1(33.33)$ & $2(66.66)$ & $3(100)$ & \\
\hline Total & $19(63.33)$ & $11(36.66)$ & $30(100)$ & \\
\hline
\end{tabular}

'p' $>0.05$ (insignificant).

Table 2: Predictive value of menopausal score.

\begin{tabular}{|lllllll|}
\hline Menopausal status & Benign $(\mathbf{n}=\mathbf{1 9})$ & Malignant $(\mathbf{n}=\mathbf{1 1})$ & $\begin{array}{l}\text { Sensitivity } \\
(\%)\end{array}$ & $\begin{array}{l}\text { Specificity } \\
(\%)\end{array}$ & $\begin{array}{l}\text { PPV } \\
(\%)\end{array}$ & $\begin{array}{l}\text { NPV } \\
(\%)\end{array}$ \\
\hline Premenopausal (score=1) & 14 & 7 & 36.36 & 73.68 & 44.44 & 66.67 \\
\hline Postmenopausal (score=4) & 5 & 4 & 36.3 &
\end{tabular}

Table 3: Distribution of subjects by CA 125.

\begin{tabular}{|c|c|c|c|c|}
\hline CA 125 & Benign $(n=19)$ & Malignant (n=11) & Total $(n=30)$ & p-value \\
\hline$<35$ & $11(91.66)$ & $1(8.33)$ & $12(40)$ & \multirow{7}{*}{0.09} \\
\hline$>35$ & $8(44.44)$ & $10(55.55)$ & $18(60)$ & \\
\hline Mean & 56.09 & 352.64 & & \\
\hline SD & 68.93 & 433.15 & & \\
\hline Median & 26.80 & 168.00 & & \\
\hline Minimum & 8.45 & 9.90 & & \\
\hline Maximum & 302.90 & 1447.70 & & \\
\hline
\end{tabular}

'p’>0.05 (insignificant).

Table 4: Predictive value of CA 125.

\begin{tabular}{|c|c|c|c|c|c|c|}
\hline CA 125 & Benign $(n=19)$ & Malignant (n=11) & $\begin{array}{l}\text { Sensitivity (\%) } \\
(95 \% \text { CI) }\end{array}$ & $\begin{array}{l}\text { Specificity (\%) } \\
(95 \% \text { CI) }\end{array}$ & PPV $(\%)$ & NPV (\%) \\
\hline$<35$ & 11 & 1 & \multirow{2}{*}{90.91} & \multirow{2}{*}{57.89} & \multirow{2}{*}{55.56} & \multirow{2}{*}{91.67} \\
\hline$>35$ & 8 & 10 & & & & \\
\hline
\end{tabular}

Table 5: Predictive value of ultrasonography score.

\begin{tabular}{|lllllll|}
\hline USG score & Benign $(\mathrm{n}=\mathbf{1 9})$ & Malignant $(\mathrm{n}=\mathbf{1 1})$ & Sensitivity $(\%)$ & Specificity $(\%)$ & PPV $(\%)$ & NPV $(\%)$ \\
\hline $\mathbf{1}$ & 10 & 1 & 90.91 & 52.63 & 52.63 & 90.91 \\
\hline
\end{tabular}

The relation between occurrence of benign and malignant disease and CA 125 was not statistically significant in the study. This could be explained by the fact that CA 125 could be raised in other inflammatory conditions of the abdomen especially in the premenopausal females who formed the bulk in present study.

The sensitivity of CA 125 in diagnosing malignancy was $90.91 \%$ and specificity was $57.89 \%$. The positive predictive value was $55.56 \%$ and negative predictive value was $91.67 \%$ in the present study.

As the p-value in this case was $0.017(<0.05)$, the relation between occurrence of benign and malignant disease with ultrasonography score was statistically significant.
The sensitivity of USG score in predicting malignancy was $90.91 \%$ and specificity was $52.63 \%$. The positive predictive value was $52.63 \%$ and negative predictive value was $90.91 \%$ in the present study.

As the p-value was 0.05 , so there was statistically significant correlation between occurrence of benign and malignant disease and tumor size in the study.

The sensitivity of tumor size in predicting malignancy was $81.82 \%$ and specificity could not be defined in this study. The positive predictive value was $32.14 \%$. The negative predictive value could not be defined as there was no benign tumor of size less than $7 \mathrm{~cm}$. 


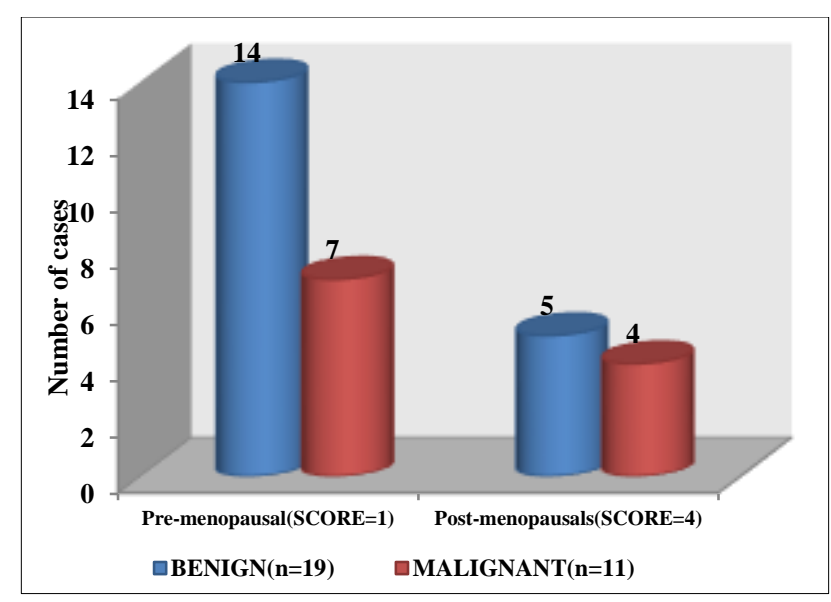

Figure 1: Distribution of subjects according to menopausal status.

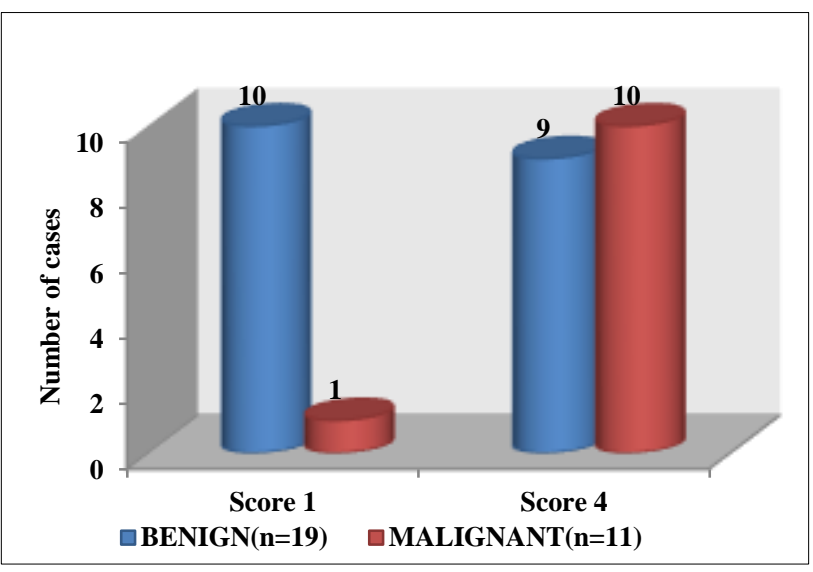

Figure 2: Distribution of subjects according to ultrasonography score.

In the present study, the value of RMI 4 was less than 450 in $17(85 \%)$ subjects with benign disease and 3 $(15 \%)$ subjects with malignant disease. The value was more than 450 in $2(20 \%)$ subjects with benign disease and $8(80 \%)$ subjects with malignant disease. The p-value for RMI 4 in the study was 0.001 which was highly significant. This concluded that the RMI 4 is a reliable tool in differentiating benign and malignant ovarian tumors.

In this study, the sensitivity of RMI 4 in predicting malignancy was $72.73 \%$ and specificity was $89.47 \%$. The positive predictive value was $80 \%$ and negative predictive value was $85 \%$.

The p-value of RMI 4 for differentiating benign and malignant tumor for serous and mucinous histology was less than 0.05 which indicated significant correlation. But for other histologist, the p-value was more than 0.05 which indicated non-significant correlation. This showed that RMI 4 was more reliable in differentiating benign and malignant tumors of serous and mucinous histology as compared to other histologies.

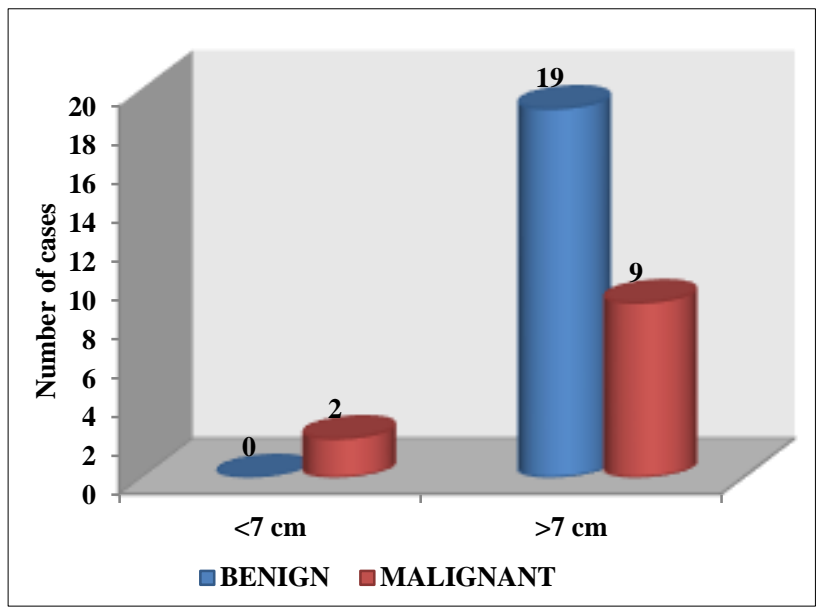

Figure 3: Distribution of subjects according to tumour size.

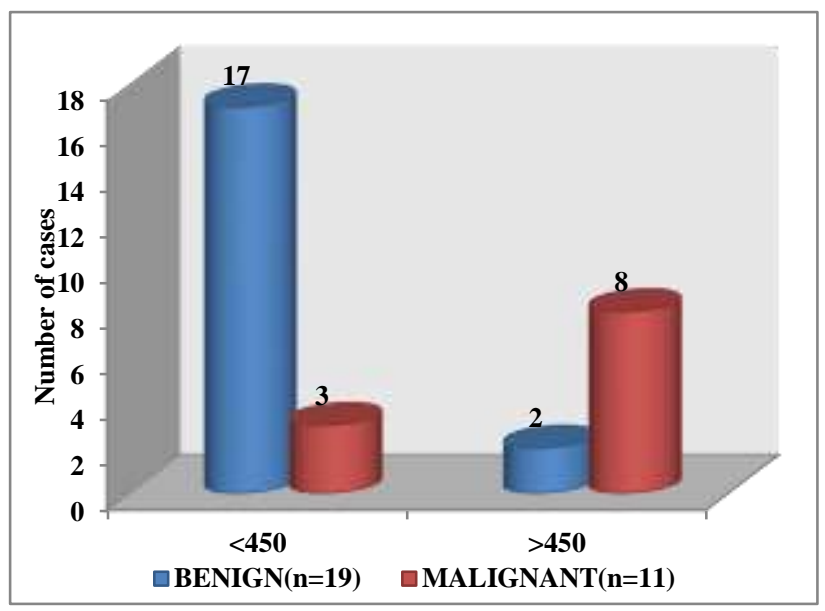

Figure 4: Distribution of subjects according to RMI-4.

Table 6: Predictive value of tumor size.

\begin{tabular}{|c|c|c|c|c|c|c|}
\hline Tumor size & Benign (n=19) & Malignant (n=11) & Sensitivity (\%) & Specificity (\%) & PPV (\%) & NPV (\%) \\
\hline$<7 \mathrm{~cm}$ & 0 & 2 & \multirow{2}{*}{81.82} & \multirow{2}{*}{0.00} & \multirow{2}{*}{32.14} & \multirow{2}{*}{0.00} \\
\hline$>7 \mathrm{~cm}$ & 19 & 9 & & & & \\
\hline
\end{tabular}

Table 7: Predictive value of RMI 4.

\begin{tabular}{|lllllll|}
\hline RMI-4 & Benign $(\mathrm{n}=\mathbf{1 9})$ & Malignant $(\mathrm{n}=\mathbf{1 1})$ & Sensitivity (\%) & Specificity (\%) & PPV & NPV \\
\hline $\mathbf{4 4 5 0}$ & 17 & 3 & 72.73 & 89.47 & 80.00 & 85.00 \\
\hline$>450$ & 2 & 8 & & & \\
\hline
\end{tabular}


Table 8: RMI 4 versus histologic type.

\begin{tabular}{|c|c|c|c|c|c|c|c|c|c|}
\hline \multirow{3}{*}{ RMI 4} & \multicolumn{9}{|c|}{ Histology type } \\
\hline & \multicolumn{3}{|c|}{ Serous $(n=9)$} & \multicolumn{3}{|c|}{ Mucinous $(n=6)$} & \multicolumn{3}{|c|}{ Others $(n=15)$} \\
\hline & $\begin{array}{c}\text { Benign } \\
(n=7)\end{array}$ & $\begin{array}{l}\text { Malignant } \\
(n=2)\end{array}$ & $\begin{array}{l}\text { Borderline } \\
\text { (0) }\end{array}$ & $\begin{array}{c}\text { Benign } \\
(\mathbf{n}=3)\end{array}$ & $\begin{array}{l}\text { Malignant } \\
(\mathrm{n}=3)\end{array}$ & $\begin{array}{l}\text { Borderline } \\
\text { (0) }\end{array}$ & $\begin{array}{l}\text { Benign } \\
(n=9)\end{array}$ & $\begin{array}{l}\text { Malignant } \\
(n=6)\end{array}$ & $\begin{array}{l}\text { Borderline } \\
(\mathbf{n}=\mathbf{0})\end{array}$ \\
\hline$<450$ & 7 & 1 & - & 3 & 0 & - & 7 & 2 & - \\
\hline$>450$ & 0 & 1 & - & 0 & 3 & - & 2 & 4 & - \\
\hline & \multicolumn{3}{|c|}{ P-value $=0.047 *$} & \multicolumn{3}{|c|}{$\mathrm{P}$-value $=0.014^{*}$} & \multicolumn{3}{|c|}{$\mathrm{P}$-value $=0.085$} \\
\hline
\end{tabular}

\section{DISCUSSION}

This study revealed the usefulness of RMI 4 to correctly discriminate between benign and malignant adnexal masses. The sensitivity, specificity, positive predictive value, negative predictive value and p-value of RMI 4 in differentiating between benign and malignant tumors were calculated.

In the present study, all the 30 subjects were divided into four age groups. Majority of the subjects belonged to age group 30-44 years. Ten subjects were less than 30 years of age and only 3 were $>55$ years of age. There was statistically insignificant correlation between age and occurrence of benign and malignant disease. This could be explained by the relatively younger age of subjects with malignant disease in the present study.

In the study conducted by Javdekar et al there was also no significant relation between occurrence of benign and malignant disease with age. ${ }^{12}$

In the present study, the sensitivity of menopausal score in diagnosing malignancy was $36.36 \%$ and specificity was $73.68 \%$. The positive predictive value was $44.44 \%$ and negative predictive value was $66.67 \%$.

In the study conducted by Javdekar et al, menopausal status had sensitivity of 41.1\% (21.61-63.99), specificity of $58.5 \%$ (43.37-72.24), positive predictive value of $29.1 \%$, and negative predictive value of $70.5 \%$ which could be compared to this study. ${ }^{12}$

CA 125 is an important marker in evaluation of ovarian masses. It is more significant in postmenopausal females as compared to premenopausal females as it can be raised in various benign inflammatory conditions in premenopausal females.

In this study, the sensitivity of CA 125 in diagnosing malignancy was $90.91 \%$ and specificity was $57.89 \%$. The positive predictive value was $55.56 \%$ and negative predictive value was $91.67 \%$ which was comparable to other studies. But there was no statistically significant correlation between CA 125 and occurrence of benign and malignant tumors ( $\mathrm{p}$-value $=0.09$ ). This could be explained by the fact that most of the subjects in this study were premenopausal where CA 125 could be raised due to other benign inflammatory conditions.

Vasilev et al also studied the serum CA 125 levels in preoperative evaluation of adnexal masses. ${ }^{13}$ Elevated levels were often associated with benign secondary pathology such as endometriosis. Their findings suggested that an elevated serum CA 125 level could not sufficiently differentiate benign from malignant tumors in the preoperative period.

In this study, Chen et al suggested that serum CA 125 levels greater than $35 \mathrm{U} / \mathrm{mL}$ were of limited clinical value as in patients with benign tumor, there was a $39.9 \%$ falsepositive rate. ${ }^{14}$

Out of 30 subjects in the present study, 11 (36.66\%) had USG score of 1 and 19 (63.33\%) had USG score of 4. In the present study, there was significant correlation between occurrence of benign and malignant disease with ultrasonography score $(\mathrm{p}$-value $=0.01)$. The sensitivity of USG score in predicting malignancy was $90.91 \%$ and specificity was $52.63 \%$. The positive predictive value was $52.63 \%$ and negative predictive value was $90.91 \%$ in the present study which was comparable to other studies.

In a study conducted by Dora et al, malignant tumors constituted $54.76 \%$ and benign tumors $45.24 \%$. $^{15}$ There were statistically significant number of malignant ovarian cancer patients where ascites and solid area was seen in USG findings $(\mathrm{p}=0.000)$.

Sassone et al in their study evaluated transvaginal sonography characteristics of ovarian disease. ${ }^{16}$ The ultrasound scoring system devised was useful in distinguishing benign from malignant masses, with a specificity of $83 \%$, sensitivity of $100 \%$, and positive and negative predictive values of 37 and $100 \%$, respectively which could be compared to this study.

In this study, the sensitivity of tumor size in predicting malignancy was $81.82 \%$ and specificity could not be defined. The positive predictive value was $32.14 \%$ and negative predictive value could not be defined.

Mohammed et al found that there was statistically significant relation between occurrence of malignancy 
and tumor size, with risk of malignancy increased as the tumor size increased. ${ }^{17}$

The objective of this study was to determine the efficacy of RMI 4 in evaluation of adnexal masses. In the present study, the value of RMI 4 was less than 450 in 17 (85\%) subjects with benign disease and $3(15 \%)$ subjects with malignant disease. The value was more than 450 in 2 $(20 \%)$ subjects with benign disease and $8(80 \%)$ subjects with malignant disease. The p-value of RMI 4 in the present study was 0.001 which was highly significant.

Yamamoto et al in their study also found that the accuracy of the RMI 4 was better than RMI 1 ( $p=0.0013)$, RMI $2(\mathrm{p}=0.0009)$ and RMI $3(\mathrm{p}=0.0013) .{ }^{11}$ The RMI 4 at a cut-off level of 450 yielded a sensitivity of $86.8 \%$, a specificity of $91.0 \%$, a positive predictive value of $63.5 \%$, a negative predictive value of $97.5 \%$, and an accuracy of $90.4 \%$.

Alanbay et al in their study compared of risk of malignancy index (RMI), CA 125, CA 19-9, ultrasound score, and menopausal status in borderline ovarian tumor. ${ }^{18}$ They found that the RMI 4 was the best method for discrimination between BOTs and benign adnexal masses and was more accurate than the other parameters.

Yenen et al did the comparison of risk of malignancy indices; RMI 1-4 in borderline ovarian tumors. ${ }^{19}$ It was concluded that RMI 4 was the best predictive RMI for preoperative discrimination of BOT at a cutoff level of 200.

Ozbay et al in their study also did comparative evaluation of the risk of malignancy index scoring systems (1-4). ${ }^{20}$ Significant $(p<0.001)$ compatibility for RMI 4 with a sensitivity of $67 \%$, PPV of $73 \%$, specificity of $92 \%$, NPV of $89 \%$ and a histopathologic correlation of $86 \%$ was obtained at the cut-off level 400.

In this study, the sensitivity of RMI 4 in predicting malignancy was $72.73 \%$ and specificity was $89.47 \%$. The positive predictive value was $80 \%$ and negative predictive value was $85 \%$. The p-value of RMI 4 for differentiating benign and malignant tumor for serous and mucinous histology was less than 0.05 which was a significant correlation but for other histologist, the pvalue was more than 0.05 which indicated insignificant correlation.

In the study conducted by Javdekar et al, the association between RMI and disease status was not statistically significant for mucinous tumors. ${ }^{12}$ While for serous tumors the association between RMI and disease status was highly significant at $p$ value of 0.0003 and that for other tumors was also statistically significant at $\mathrm{p}$ value of 0.0043 .

\section{CONCLUSION}

It is concluded from the study that RMI 4 is a reliable tool for differentiating benign and malignant tumors. It is a simple, reliable and applicable method in the primary evaluation of patients with adnexal masses.

\section{Funding: No funding sources}

Conflict of interest: None declared

Ethical approval: The study was approved by the Institutional Ethics Committee

\section{REFERENCES}

1. ACOG practice bulletin. Management of adnexal masses. Obstet Gynecol. 2007;110:201-14.

2. Scully RE, Sobin LH. Histological typing of ovarian tumours. Springer Sci Business Media; 1999.

3. Taylor HC. Malignant and semi-malignant tumors of the ovary. Obstet Gynecol. 1929;48:204-30.

4. Gwinn ML, Lee NC, Rhodes PH, Layde PM, Rubin GL. Pregnancy, breast feeding, and oral contraceptives and the risk of epithelial ovarian cancer. J Clin Epidemiol. 1990;43:559-68.

5. Zorn KK, Tian C, McGuire WP, Hoskins WJ, Markman M, Muggia FM, et al. The prognostic value of pretreatment CA 125 in patients with advanced ovarian carcinoma. Cancer. 2009;115(5):1028-35.

6. Medeiros LR, Rosa DD, da Rosa MI, Bozzetti MC. Accuracy of CA 125 in the diagnosis of ovarian tumors: a quantitative systematic review. Eur J Obstet Gynecol Reprod Biol. 2009;142:99-105.

7. Engelen MJ, de Bruijn HW, Hollema H, ten Hoor KA, Willemse PH, Aalders JG, et al. Serum CA 125, carcinoembryonic antigen and CA 19-9 as tumor markers in borderline ovarian tumors. Gynecol Oncol. 2000;78:16-20.

8. Meys EM, Kaijser J, Kruitwagen RF, Slangen BF, Van Calster B, Aertgeerts B, et al. Subjective assessment versus ultrasound models to diagnose ovarian cancer: a systematic review and metaanalysis. European J Cancer. 2016;58:17-29.

9. Van Calster B, Timmerman D, Bourne T, Testa AC, Van Holsbeke C, Domali E, et al. Discrimination between benign and malignant adnexal masses by specialist ultrasound examination versus serum CA125. J National Cancer Inst. 2007;99(22):1706-14.

10. Chan L, Lin WM, Uerpairojkit B, Hartman D, Reece EA, Helm W. Evaluation of adnexal masses using three-dimensional ultrasonographic technology: preliminary report. J Ultrasound Med. 1997;16(5):349-54.

11. Yamamoto $\mathrm{Y}$, Yamada R, Oguri H, Maeda N, Fukaya T. Comparison of four malignancy risk indices in the preoperative evaluation of patients with pelvic masses. Eur J Obstet Gynecol Reprod Biol. 2009;144:163-7. 
12. Javdekar R, Maitra N. Risk of malignancy index (RMI) in evaluation of adnexal mass. J Obstet Gynecol India. 2015;65(2):117-21.

13. Vasilev SA, Schlaerth JB, Campeau J, Morrow CP. Serum CA-125 levels in preoperative evaluation of pelvic masses. Obstet Gynecol. 1988;71:751-6.

14. Chen DX, Schwartz PE, Li XG, Yang Z. Evaluation of CA-125 levels in differentiating malignant from benign tumors in patients with pelvic masses. Obstet Gynecol. 1988;72:23-7.

15. Dora SK, Dandapat AB, Pande B, Hota JP. A prospective study to evaluate the risk malignancy index and its diagnostic implication in patients with suspected ovarian mass. J Ovarian Res. 2017;10(1):55.

16. Sassone AM, Timor-Tritsch IE, Artner A, Westhoff C, Warren WB. Transvaginal sonographic characterization of ovarian disease: evaluation of a new scoring system to predict ovarian malignancy. Obstet Gynecol. 1991;78(1):70-6.

17. Mohammed ABF, Ahuga VK, Taha M. Validation of the risk of malignancy index in primary evaluation of ovarian masses. Middle East Fertil Society J. 2014;19(4):324-8.
18. Alanbay İ, Akturk E, Coksuer H, Ercan M, Karaşahin E, Dede M, et al. Comparison of risk of malignancy index (RMI), CA 125, CA 19-9, ultrasound score, and menopausal status in borderline ovarian tumor. Gynecol Endocrinol. 2012;28(6):478-82.

19. Yenen MC, Alanbay I, Akturk E, Ercan CM, Coksuer H, Karaşahin E, et al. Comparison of risk of malignancy indices; RMI 1-4 in borderline ovarian tumor. European J Gynaecol Oncol. 2011;33(2):16873.

20. Ozbay PO, Ekinci T, Caltekin MD, Yilmaz HT, Temur M, Yilmaz O, et al. Comparative evaluation of the risk of malignancy index scoring systems (1-4) used in differential diagnosis of adnexal masses. Asian Pac J Cancer Prev. 2015;16:345-9.

Cite this article as: Kaur A, Sharma S, Singh S. Role of risk of malignancy index 4 in evaluation of adnexal masses. Int J Reprod Contracept Obstet Gynecol 2020;9:3818-24. 